\title{
Earnings Mobility, Inequality, and Economic Growth in Argentina, Mexico, and Venezuela
}

\author{
Gary S. Fields \\ Cornell University \\ Robert Duval-Hernandez \\ University of Cyprus \\ Samuel Freije \\ Universidad de las Americas \\ Maria Laura Sanchez Puerta \\ World Bank
}

\begin{abstract}
This paper examines changes in individual earnings during positive and negative growth periods in three Latin American economies: Argentina, Mexico, and Venezuela. We ask two major questions. First, do panel income changes favor the income recipients who started at the top of the income distribution ("divergent mobility") or those who started at the bottom ("convergent mobility")? And second, are the groups that are found to gain the most when the economy is growing those that are found to lose the most when the economy is contracting ("symmetry of mobility") or is the pattern asymmetric in the sense that the same groups do best both in times of economic growth and in times of economic decline? We find support for the divergent mobility hypothesis only in scattered years in the cases of Mexico and Venezuela and no support at all in the case of Argentina. Rather, earnings mobility is most frequently convergent or neutral in all three countries. As for the symmetry of mobility hypothesis, we find that it is rejected in nearly all cases; rather, those groups that gain the most when the economy is growing are also the ones that gain the most or lose the least when the economy is contracting. Furthermore, we discuss how the absence of divergence reconciles with rising inequality in the countries under study.
\end{abstract}

Keywords Earnings mobility • Income convergence • Latin America

\section{Motivation and Questions}

Who gains the most income when economies grow? Who loses the most income when economies contract? Are those groups that gain the most income in good times the ones that lose the most income in bad times? In this paper, we answer these questions for the changes in labor market earnings for three Latin American countries: Argentina, Mexico, and Venezuela.

The literature offers two distinct but complementary ways of answering questions like these. The more traditional way is to compare data from anonymous cross-sections. Exemplary of this tradition are Kuznets's [23] seminal work relating inequality and growth and the literature on 
pro-poor growth and the development of growth incidence curves (e.g., [28]. These literatures are surveyed in [3]. More recently, a growing strand of work uses panel data to follow the same individuals or households over time and gauge changes in their economic circumstances; [21] provide a comprehensive overview.

The two types of analysis -anonymous cross sections and panel data - might produce the same qualitative results - for example, the anonymous rich gaining more than the anonymous poor and the panel rich gaining more than the panel poor - but this is not necessarily to be expected. To see why, consider a benchmark case and deviations from it.

Henry Aaron [1] famously said that watching the distribution of income change is "like watching the grass grow." Picture, then, a process of economic growth which leaves the Lorenz curve unchanged or approximately so. Suppose that within an unchanged Lorenz curve, each income recipient were to keep the same position within the income distribution. In this case, the panel data would show the same percentage change in income for each panel person. And, of course, in a time of economic growth, the same percentage change for everyone would mean a larger gain in currency units (here, pesos in Argentina and Mexico, bolivares in Venezuela) for the people who started higher up in the income distribution than for those who started further down. Such a pattern would be what we call "divergent mobility" in real local currency units.

Researchers have many reasons to expect that most panel income changes would be fairly small: among them, most people deriving their incomes from the same sources over time, most people working in the same jobs from one year to the next, and most income sources yielding more or less the same incomes over time. Accordingly, nearly all quantile transition matrices have shown the majority of entries lying along the principal diagonal, with (in a quintile transition matrix) the $(5,5)$ cell exhibiting the highest frequency and the $(1,1)$ cell the second highest frequency.

As for the pattern of deviations from proportionality, numerous forces are at work, some going in one direction and some the other. Consider first those that lead to divergence. The theory of cumulative advantage posits that individuals with higher incomes and earnings in the base year experience the largest earnings gains [25]. Wealthier individuals' ownership of physical and human capital, access to social and political connections, and greater ability to borrow and save, could all contribute to cumulative advantage. Complementing cumulative advantage in contributing to divergent mobility is the notion of poverty traps [5]. According to this theory, those individuals who lack a minimum level of human, physical, and social assets are consigned to a life in poverty from which they cannot escape. Yet another factor that may contribute to larger gains for the initially well-to-do compared with others is labor market twist. This idea holds that in an increasingly globalized and technology-dependent world, the demand for skills is outpacing the available supply, bidding up the earnings of skilled workers while lowering the relative earnings of the unskilled, with skill-biased technical change propelling individuals with the highest human and physical capital endowments ahead the most [2]. Together, the preceding factors reinforce one another, exemplifying positive feedback in changes in economic well-being, defined by Nobel laureate James Meade ([24], p. 155) as "self-reinforcing influences which help to sustain the good fortune of the fortunate and the bad fortune of the unfortunate." 
On the other hand, there are also reasons to expect convergent income changes. For life cycle reasons, young people will disproportionately experience income gains and older people income losses. Some people are casual employees, working some days and weeks and not others; whether one has work is one source of instability. Other working people are regularly engaged in work in which unstable earnings are the norm, and these people do well some of the time and badly some of the time. And in a segmented labor market, some people have the good fortune of being able to move up out of the poorer jobs and into better ones while others have the exact opposite experience.

In sum, the benchmark case (approximately unchanged Lorenz curves, little movement within the income distribution) could hold but it need not. Divergent and convergent forces are pulling in opposite directions.

So far, we have discussed the case of positive economic growth. Economic growth is positive in most countries most of the time, but what if economic growth is negative? Again, suppose that the Lorenz curve remains unchanged and that each income recipient keeps the same position in the income distribution as before. In times of economic decline, the income losses would be largest in pesos or bolivares for those who started highest in the income distribution compared to those who started further down - the exact opposite of what would be encountered in times of economic growth. We term the opposing patterns in times of positive and negative economic growth symmetry of mobility. But some of the factors mentioned above - in particular, cumulative advantage, poverty traps, and labor market twist - work in the other direction; in other words, Meade's positive feedback influences operate so that those who started ahead remain ahead even in times of economic decline, leading to asymmetry of mobility.

We thus have two major questions. First, do panel income changes favor the income recipients who started at the top of the income distribution (divergent mobility) or those who started at the bottom (convergent mobility)? And second, are the groups that are found to gain the most when the economy is growing those that are found to lose the most when the economy is contracting (symmetry of mobility) or is the pattern asymmetric in the sense that the same groups do best both in times of economic growth and in times of economic decline?

\section{Contributions to the empirical literature on Latin America}

This paper uses panel data to answer the divergent/convergent mobility question and the symmetry/asymmetry of mobility question for three Latin American economies: Argentina, Mexico, and Venezuela. We study the variations in patterns of individual earnings changes over a large number of one-year panels in each of the three countries. In most but not all years covered by this study, economic growth was positive; and in several years, the relative inequality of earnings rose, in our three countries and in Latin America as a whole [16]. Given these macroeconomic changes and given our sense that most people remain approximately where they were within the income distribution, we expect to find two patterns in panel data: first, that panel earnings changes would be divergent in percentages on several occasions, and second that panel earnings changes would be divergent in the country's currency units almost all the time - that is, 
on average, the higher is one's initial earnings, the higher is one's earnings gain in pesos or bolivares.

Throughout this paper, earnings mobility is measured as changes in real labor market earnings in local currency. We use both changes in earnings as well as changes in log-earnings (the latter to approximate proportional changes). We adopt two measures of initial advantage: one based on the reported initial level of earnings, and another one based on the component of earnings predicted by socio-demographic characteristics permanently attached to the worker. This last measure is a proxy of longer-term advantage, and permits a mobility analysis that is less sensitive to transitory changes in earnings and to measurement error.

For the most part, to the extent that earnings gains and losses of different income groups in positive growth and negative growth periods have been studied in Argentina, Mexico, and Venezuela, the answers have mainly relied on comparable cross sections [16]. In this way, researchers have looked at anonymous individuals and households: e.g. those in the poorest $20 \%$ of the income distribution versus others, thus comparing the evolution of income distribution through the use of growth incidence curves. This type of analysis does not link changes in inequality with the evolution of individual incomes over time.

In contrast, in this paper, we look at panel data and calculate earnings changes for each panel person, thus removing anonymity. The study of mobility patterns in labor markets in developing economies is still a fresh area of research where much remains to be learned; see [6] for a review of the literature on developing countries in general and our paper [13] for Latin American countries in particular. ${ }^{1}$ More recent studies for these economies include Fields and Sanchez Puerta [14], Cuesta et al. [9] and Krebs et al. [22].

\section{Data and economic context}

Argentina, Mexico, and Venezuela are chosen for our mobility study both for reasons of data availability and for inherent interest. The available data sets permit the same questions to be answered in a consistent manner in each of the three countries. We are able to measure the changes in real earnings from a given month in one year to the corresponding month a year later. These one-year-long panels begin in 1996 for all urban Argentina, in 1987 for all urban Mexico, and in 1994 for all Venezuela. Moreover, each country has a large number of comparable panels - seven in the case of Argentina, eighty-five in the case of Mexico, and fourteen in the case of Venezuela - ranging over widely different macroeconomic conditions.

The data sources for the three countries are similar in a number of respects. In each, the sample under investigation consists of men and women who were in the labor force both in a given survey and in a follow-up survey one year later. The dependent variables in each case are changes in labor earnings and changes in log-earnings from one year to the next. In each case, earnings are measured in real local currency units (i.e., 1999 pesos for Argentina, 2002 pesos for Mexico, and 1996 bolivares for Venezuela). The surveys also contain information on a set of demographic characteristics like gender, age, education, and geographic region indicators that will be used to 
predict longer-term earnings (see Section 4 below). To capture earnings changes among workers and to exclude new labor force entrants and retirees, we limit the analysis to individuals aged 25 to 60 in the base year.

For Argentina, the data used come from the Encuesta Permanente de Hogares (EPH or Permanent Household Survey), a rotating panel following urban households for a maximum of a year and a half. For the years used in this paper, the survey was conducted in May and October each year in provincial capitals and areas with more than 100,000 inhabitants for a total of 28 urban areas. Argentina is predominantly urban (86\%); just the May-to-May changes are used here. The urban areas surveyed represent 61 percent of the country and 71 percent of urban areas. The survey contains detailed questions on employment and incomes, together with information on household demographics, housing questions, and questions on education. The survey methodology changed after May: 2003; therefore, the years used in this paper are 1996-97 to 2002-03 for all urban Argentina.

For Mexico, the data used come from the Encuesta Nacional de Empleo Urbano (ENEU or National Urban Employment Survey), a survey conducted on urban households to trace labor market characteristics in urban areas. This survey is a rotating panel with quarterly data for five periods. In order to maintain consistent geographical coverage over time, the present analysis is based only on the cities that remain in the panel throughout the 1987-2010 period. The urban centers surveyed cover 35 percent of the total population and about 57 percent of the population living in areas with more than 15 thousand inhabitants. Although the coverage of the ENEU has expanded to now survey rural areas as well, we only use data on urban households since the rural panels didn't exist for the first fifteen years of our data. ${ }^{2}$ In 2005 the ENEU was replaced by the Encuesta Nacional de Ocupacion y Empleo (ENOE or National Survey on Occupation and Employment), which updated the questionnaire and the sampling scheme of the ENEU. However, for the most part the trends observed in the key variables used in this study remain comparable with the ones previous to 2005 .

For Venezuela, the data source is the Encuesta de Hogares por Muestreo (EHM or Household Sample Survey). This survey has been conducted twice a year since 1969. For this study, the data run from 1994-95 to 2003-2004. It is a nationwide survey, initially intended for measuring unemployment and other characteristics of the labor market. ${ }^{3}$ Currently, the EHM is a multipurpose survey that includes questions not only about labor market variables such as labor force participation, earnings and unionization but also about family composition and characteristics of dwellings. Every six months, one sixth of the sample is replaced by a new set of households from the same sampling cluster. This feature enables researchers to produce panel data for those dwellings that remain in the sample up to a maximum of six observation data points. Since the household identification code was not consistent during 1997-98 and 2000-02, these data points needed to be dropped. 


\subsection{Growth and Inequality Index}

Before presenting the empirical methods followed in this paper, we briefly discuss the evolution of GDP growth and earnings inequality for our three countries. More details can be found in the supporting Online Appendix of the paper.

Unfortunately, during our periods of study our three economies experienced not only positive economic growth but severe economic downturns. Between the years 1996 and 2003, the Argentinean economy experienced extraordinary macroeconomic variability. During the midnineties it experienced moderate growth followed by a recession at the end of the decade and a severe collapse of the economy at the end of 2001. In the case of Mexico, the economy experienced an upward trend in real GDP from 1987 to 1994 thanks to the liberalization reforms implemented in those years. In December 1994, the Peso crisis hit the economy and output suffered a sharp downturn, from which it started recovering rapidly. From 1997 onwards, the Mexican economy continued its slow growth, with temporary downturns around the years 2001-2002 and 2009. Finally, the Venezuelan economy experienced years of moderate economic growth from 1995 to 1997 and from 2000 to 2001. Each of these growth episodes was followed by a moderate to severe contraction. By the fourth quarter of 2002 the economy rebounded and in 2003 it experienced one of the highest growth rates of the decade.

During the years of this study, absolute and relative earnings inequality changed substantially in the three countries. Absolute inequality was fluctuating in Argentina and Venezuela, while in Mexico it had an inverted-V pattern. As for relative inequality, it rose steadily in Argentina with the exception of the last year, in Mexico it presented an inverted-V pattern, and in Venezuela different relative inequality measures display crossing patterns.

\section{Empirical Methods}

The dependent variable in this study is one-year mobility for each country, i.e., change in earnings and log-earnings for the same individuals from a given month in one year to that same month a year later. Changes in log-earnings are used to approximate proportional changes. The analysis of these proportional changes is important because a given change in income will have a very different impact on well-being depending on whether the individual is poor or rich, e.g., during periods of economic decline a reduction in 100 pesos might represent a drastic change for a poor person, but not for a rich one. For unemployed individuals and individuals with zero earnings we impute them an earnings level of 1 peso/bolivar in order to avoid excluding them from the sample when conducting the analysis of log-earnings.

The data for one-year mobility are analyzed in a number of ways, depending on the hypothesis being tested. The tests for divergence or convergence are based on a) a pooled sample, which uses all of the one-year-long panels, as well as b) each individual panel. The tests for symmetry/asymmetry involve a comparison of all of the positive-growth years with all of the negative-growth years. 


\subsection{Earnings dynamics and the divergence of earnings hypothesis}

We start by displaying quintile mobility profiles. These tables show the relationship between earnings and log-earnings change and initial reported earnings quintile groups, over the whole sample and for periods of growth and decline separately. They are the mobility have larger earnings (or log-earnings) changes and whether these patterns are consistent over periods of growth and recession.

Next we perform a regression analysis over each of our yearly panels to test in more detail the divergence of earnings hypothesis. To motivate this analysis consider the following simple earnings dynamics model.

Let $Y_{t}$ denote the earnings of an individual in the population at time $t^{4}$ As previously mentioned, our goal is to estimate how an initial advantage in earnings relates to earnings changes. With our data containing individual observations for two periods one year apart, it is natural to formulate a population regression model like

$$
\Delta Y_{t}=Y_{t-1}=\beta_{0}+\beta_{1} Y_{t-1}+U_{t}
$$

The parameters of this model provide an answer to the question of whether initially advantaged individuals (in terms of earnings) are getting ahead faster than the rest, or alternatively whether the earnings of poorer and richer workers are converging. In particular, the population parameter $\beta_{1}$ measures the expected difference in $\Delta Y_{t}$ for two individuals who differ by one peso or bolivar in their initial earnings. If $\beta_{1}<0$ it means that earnings changes are negatively related to initial earnings, in which case from one year to the next we would observe convergence in the incomes of initially advantaged and disadvantaged workers. If, on the other hand, $\beta_{1}>0$, this would signify greater earnings gains the greater is initial advantage and hence to a divergent process of earnings dynamics. Finally, if $\beta_{1}=0$, earnings changes would on average be unaffected by the initial advantage of the worker.

While this model is simple and intuitive, we should be careful when interpreting it. In particular, it is possible to observe negative values of $\beta_{1}$ if for instance workers are subject to individual transitory earnings shocks that wear out over time. In other words, in the short run we might observe that earnings are converging just because workers who received an initial positive (negative) earnings shock are now adjusting back to their lower (higher) permanent level of earnings, even if the longer-term earnings do not converge in general. Although strictly speaking this does not create any problem to the model in Eq. 1, we usually do not want to confound transitory adjustments in earnings with a more meaningful convergent process in earnings trajectories over a longer period of time.

To investigate whether convergence between rich and poor is taking place in a more permanent sense, we need to somehow eliminate the impact of earnings reverting to the conditional mean. Thus we need to come up with an operational definition of transitory earnings. To do so, we propose a simple model of earnings determination that can be estimated with short-lived panel datasets like ours. 
In particular, we decompose $Y_{t}$ as the sum of a component related to characteristics permanently attached to the worker and another component that will be considered transitory earnings. In other words, we propose the model

$$
Y_{t}=Z \gamma_{t}+\delta \tau_{t}+\epsilon_{t}
$$

where $Z$ is a $(1 \times k)$ vector of observable socioeconomic characteristics permanently attached to an individual (like gender, age, education level, etc.), $\delta$ is a scalar capturing unobserved characteristics permanently attached to the individual, $\gamma_{t}$ and $\tau_{t}$ are time-varying coefficients capturing the influence of these characteristics on earnings, and et is the transitory shock component previously mentioned. Thus, $Y_{t}^{p}=Z \gamma_{t}+\delta \tau_{t}$ forms the component of earnings associated with permanent characteristics of the worker, and the remaining $\epsilon_{t}$ will be dubbed transitory earnings. Note that we allow $y_{t}^{p}$ to be time-varying, since the coefficients associated to these permanent characteristics can change across periods.

To give empirical content to this model, we need to be explicit about the relation between each of these components. In particular, we assume that in the population these three components are uncorrelated among themselves, i.e.,

$$
\operatorname{cov}\left(Z_{j}, \delta\right)=\operatorname{cov}\left(Z_{j}, \epsilon_{t}\right)=\operatorname{cov}\left(\delta, \epsilon_{t}\right)=0 \forall_{t}, \forall_{j}=1, \ldots, k .
$$

Furthermore, we will assume that $\epsilon_{t}$ follows an $\operatorname{AR}(1)$ process, i.e. ${ }^{5}$

$$
\epsilon_{t}=\rho \epsilon_{t-1}+v_{t} \quad v_{t} \sim \text { iid }\left(0, \sigma_{v}^{2}\right) \quad|p|<1 .
$$

The assumptions of uncorrelatedness between the different components of earnings imply that we cannot give a structural interpretation to the coefficient vector $\gamma_{t}$. These assumptions are not too restrictive for the purpose at hand, insofar as we are not trying to estimate the returns to socioeconomic characteristics of the worker, but rather implement a decomposition of the embodied permanent advantage of workers.

The transitory earnings term will contain earnings shocks uncorrelated with the vector $Z$ and the scalar $\delta$, which are the characteristics permanently attached to the worker. We implement this definition of transitory shocks because we lack a long series of yearly observations for each individual in the panel. If we had such a dataset we could in principle define as transitory those shocks whose effects die out over time or that are uncorrelated with some long-run trend in earnings. ${ }^{6}$

The AR (1) assumption made on this transitory shock is a common specification in the income mobility literature. Although many papers include more general ARMA $(\mathrm{p}, \mathrm{q})$ structures, such structures cannot be identified with our short-lived panels.

With this framework, we can now proceed in two stages, first estimating Eq. 2 in period $t-1$ to get the component of initial earnings associated with permanent characteristics of the worker and then using the predicted values of this regression in a second stage where we estimate the relationship between $\Delta Y_{t}$ and $Y_{t-1}^{p}$ : 


$$
\Delta Y_{t}=\alpha_{0}+\alpha_{1} Y_{t-1}^{p}+e_{t} .
$$

In Eq. 3, the parameter a1 captures how earnings changes are related to the component of initial earnings associated with permanent characteristics of the worker. Since this parameter is not affected by transitory shocks reverting to the mean, it will be a better measure of how earnings changes are related to a more permanent measure of initial advantage.

In practice, we do not observe the unobserved individual-specific shocks contained in 8 in Eq. 2, which implies that we can only estimate in a first stage the component of earnings associated with observed permanent characteristics, namely $Y_{t-1}^{Z}=Z \gamma_{t-1}$. However, given the orthogonality between $\delta$ and $Z$, it will suffice to know $Y_{t-1}^{Z}$ in order to be able to consistently estimate $\alpha_{1}$ in a regression

$$
\Delta Y_{t}=\alpha_{0}+\alpha_{1} Y_{t-1}^{Z}+v_{t}
$$

This claim, as well as a full exposition of the econometric model is presented in detail in the Online Appendix of the paper.

In summary, we can use a Two-Stages Least Squares (2SLS) procedure to consistently estimate our parameter of interest $\alpha_{1}$, namely the impact of a more permanent measure of earnings on earnings changes.

In our empirical specification the vector $\mathrm{z}$ of observable permanent characteristics of the worker includes age, gender, education and region. ${ }^{7}$

\subsection{Testing the symmetry of gains and losses hypothesis}

As previously mentioned, we formulate the symmetry of gains and losses hypothesis, which is the idea that those earnings groups which experience larger positive earnings gains when the economy grows are the same as those that experience larger earnings losses when the economy contracts.

In the context of a regression equation like Eq. 1, which relates earnings changes to initial earnings we can test whether there is symmetry of gains and losses for each of our countries by pooling the data from several panels for years of growth and recession for a given economy. In particular, we can estimate a model

$$
\Delta Y=\beta_{0}+\beta_{1} Y_{t-1}+\beta_{2} N G+\beta_{3} Y_{t-1} * N G+u,
$$

where $N G$ is a dummy indicating whether in the year in which earnings changes are being considered, GDP growth was negative. ${ }^{8}$ In other words, this model assumes that earnings changes during periods with positive growth are given by the equation

$$
\Delta Y=\beta_{0}+\beta_{1} Y_{t-1}+u,
$$

while during periods with negative growth the equation is

$$
\Delta Y=\left(\beta_{0}+\beta_{2}\right)+\left(\beta_{1}+\beta_{3}\right) Y_{t-1}+u .
$$

With an equation like Eq. 5, we can test the aforementioned symmetry of gains and losses hypothesis. In particular, if during a period of positive growth richer individuals experience the 
largest earnings gains, i.e. if $\beta_{1}>0$, then symmetry would imply that it is also the rich that lose the most during periods of negative growth. In terms of our Eq. 5, this would mean that $\beta_{1}+\beta_{3}<$ 0 , or simply $\beta_{3}<-\beta_{1}<0$.

Similarly, if during a period of positive growth the richer individuals experience the smallest earnings gains, i.e. if $\beta_{1}<0$, then symmetry of mobility would imply that it is also the richer individuals who lose the least during periods of negative growth. In terms of our Eq. 5, this would mean that $\beta_{1}+\beta_{3}>0$, or $\beta_{3}>-\beta_{1}>0$.

These two conditions can be tested with a one-tailed t-test over the parameters estimated from Eq. 5. In particular we can test the symmetry of gains and losses hypothesis by testing the following one-sided hypotheses:

\begin{tabular}{|c|c|c|}
\hline Parameter & $\mathrm{H}_{0}$ & $\mathrm{H}_{1}$ \\
\hline$\beta_{1}>0$ & $\beta_{1}+\beta_{3} \leq 0$ & $\beta_{1}+\beta_{3}>0$ \\
\hline$\beta_{1}<0$ & $\beta_{1}+\beta_{3} \geq 0$ & $\beta_{1}+\beta_{3}<0$ \\
\hline
\end{tabular}

Since these are tests for a linear combination of the parameters $\beta_{1}$ and $\beta_{3}$ they can be performed with a one-sided t-test with $n-k-1$ degrees of freedom. The specific form of the $\mathrm{t}$-statistic is the following

$$
t=\operatorname{sgn}\left(\hat{\beta}_{1}\right) \frac{\hat{\beta}_{1}+\hat{\beta}_{3}}{\operatorname{se}\left(\hat{\beta}_{1}+\hat{\beta}_{3}\right)}
$$

where $\operatorname{sgn}(x)$ is a function that takes value 1 if $x$ is positive, 0 if $x=0$, and -1 if $x<0$. By premultiplying the ratio by the sign of $\beta_{1}$ we ensure this statistic will be positive if the estimated patterns are asymmetric.

A rejection of the null will be taken as evidence of asymmetric mobility patterns over the business cycle. ${ }^{9}$

\subsection{Robustness checks}

\subsubsection{Measurement error}

So far we have assumed that earnings were measured without error. However, based on validation data in developed countries, we know that this assumption is seldom true. Furthermore, measurement error in earnings is rarely just random noise as the traditional Classical Measurement Error model used to assume (see Bound et al. [8]).

The analysis of the impact of a general form of measurement error on the regression estimates of Eq. 1 has been presented in detail in Gottschalk and Huynh [19]. Using data for the U.S.A., the authors find that measurement error leads to a substantial understatement of inequality (due to mean reversion in the measurement error), but estimates of our parameter $\beta_{1}$ in Eq. 1 are largely unaffected by such error when dealing with a model of log-earnings. 
The reason for such a lack of impact on the OLS estimates of Eq. 1 with log-earnings is that with nonclassical measurement error, the attenuation effect on the parameter estimates is offset by the strong correlation between measurement errors across periods.

The consequences of nonclassical measurement error on the estimates arising from the model in Eq. 4 are derived analytically in the Online Appendix of the paper. From that derivation we can conclude that measurement error will have no impact on the estimates of $\alpha_{1}$ as long as this error is uncorrelated with the observed permanent characteristics included in the vector $Z$.

To the extent that a substantial part of the measurement error occurs due to reactions to transitory fluctuations in earnings (see Bound et al. [7], and Gottschalk and Huynh [19]), it is plausible that the inconsistency in our 2SLS estimates when earnings are measured with error is small.

Nevertheless, lacking any validation data for our countries (and for any developing country to the best of our knowledge), we cannot judge whether the conclusions found by Gottschalk and Huynh for Eq. 1 or the conditions mentioned in the previous paragraph hold in our data. At best, we can report on the analytical implications of a general form of measurement error on our estimates and refer to the available empirical evidence for developed nations.

Other methods for dealing with measurement error in the context of earnings changes regressions include instrumenting using either second measurements of earnings or variables that are caused by earnings [17] and constructing pseudo-panels and tracking the mobility of average cohort earnings [4]. ${ }^{10}$ While these papers correctly point out that 2SLS does not necessarily leads to consistent estimates of $\beta_{1}$ in the presence of measurement error, we contend that the parameter $\alpha_{1}$ is an interesting economic object on its own, one that on many occasions can be even more interesting than the original $\beta_{1}$ itself. $^{11}$

In particular, $\alpha_{1}$ provides an estimate of how earnings changes are related to a more permanent measure of initial advantage, and hence it gives a measure of mobility cleaner from the mean-reverting impact of transitory shocks and cleaner from measurement error too.

\subsubsection{Additional specifications}

In addition to the methods previously discussed, we estimated four additional models.

One robustness check we performed was to estimate the model in Eq. 4 adding sector of economic activity (formal/informal) as a regressor among the set of characteristics of the worker included in the vector $Z$. Although for many individuals, the sector of economic activity will be a transitory state, for some others it will be more permanent as they will tend to stay in one sector for most of their active life.

An alternative method that we explored involved approximating the individual's longerterm earnings by averaging their earnings over several periods observed in the panel. This method captures the impact of both observable factors and unobservable time-invariant characteristics and it will work best if the panel has many observations per individual (i.e. if $T$ is large) and if these observations are spaced widely over time. Under these conditions the effects of transitory income 
fluctuations and measurement error would be averaged out and their impact would be minimal. We performed these estimations but do not regard them as our preferred specification because in our case $T$ is not very large and the time observations are close to one another. ${ }^{12}$

We also estimated our key models dropping from the sample the individuals who had earnings equal to zero in either the initial or the final period.

Finally, we estimated an alternative version of our predicted model where we "purged" earnings of life-cycle effects before estimating Eq. 4.

\section{Results}

\subsection{Mobility profiles}

Tables 1, 2 and 3 provide a first exploration of the mobility data and give preliminary answers to the questions posed in Section 1. In these tables we display mobility profiles for the population classified according to their quintile group in the initial earnings distribution. This exercise is presented for earnings in levels for all years pooled together. ${ }^{13}$

In these mobility profiles, we observe that for all the countries larger positive gains (smaller negative losses) are observed for individuals at the bottom of the initial period earnings distribution. This evidence goes against the divergence hypothesis. ${ }^{14}$

As a first test of the symmetry hypothesis, these same tables also separate out periods of positive and negative GDP growth. We find convergent earnings changes in both the positive growth and the negative growth periods. This is evidence against the symmetry of gains and losses hypothesis, since the same income groups that gain the most when positive growth takes place are the ones who gain the most (lose the least) when there is negative growth.

\subsection{Regression-based tests: divergence of earnings}

A more precise test of the divergence of earnings hypothesis is obtained by estimating Eq. 1, namely regressing earnings change on initial reported earnings for each country for each one-year panel under the assumption of linearity. These point estimates, along with their $95 \%$ confidence intervals, are reported in the left column of Fig. 1. The right column of that same figure presents the estimates for the regression for changes in log-earnings on initial log-earnings. In all years and for all countries, the regression coefficients are significantly negative. Thus, when initial reported earnings and log-earnings are used as a measure of initial advantage, in all three countries, it is those with the lowest initial reported earnings who exhibit the largest average earnings gains. The divergence of earnings hypothesis for initial reported earnings is decisively rejected by this test.

As noted above, this negative relationship between earnings change and initial earnings could be the result of earnings in any given year adjusting back to their longer-term levels after a transitory shock. This negative relationship could also be the result of measurement error.

Accordingly, we approximate longer-term earnings using the prediction method described in Section 4 and use these as regressors in the earnings change Eq. 4. The regression coefficients 
for this exercise are plotted in Fig. 2, on the left side for earnings change in currency units on initial predicted earnings in currency units, and on the right side for change in log-earnings on initial predicted log-earnings.

Table 1 Average earnings changes by initial reported earnings quintile group

\begin{tabular}{|c|c|c|c|c|}
\hline & Mean & Std. Dev. & Obs. & $\mathrm{H}_{01}$ \\
\hline \multicolumn{5}{|l|}{ Positive and negative growth years combined } \\
\hline Total population & -30.5 & 527.4 & 53,349 & $* * *$ \\
\hline Breakdown by initial reported earnings quintile group & $\mathrm{H}_{02}$ : **** & & & \\
\hline Lowest quintile group & 226.6 & 488.7 & 11,211 & $* * *$ \\
\hline Quintile group 2 & 4.5 & 192.5 & 10,954 & $* * *$ \\
\hline Quintile group 3 & -28.5 & 240.5 & 11,237 & $* * *$ \\
\hline Quintile group 4 & -67.7 & 332.6 & 9,895 & $* * *$ \\
\hline Highest quintile group & -321.2 & 913.7 & 10,052 & $* * *$ \\
\hline \multicolumn{5}{|l|}{ Periods of positive growth } \\
\hline Total population & 4.4 & 504.8 & 22,422 & $* * *$ \\
\hline Breakdown by initial reported earnings quintile group & $\mathrm{H}_{02}: * * *$ & & & \\
\hline Lowest quintile group & 243.2 & 478.2 & 4,537 & $* * *$ \\
\hline Quintile group 2 & 25.1 & 218.2 & 4,678 & $* * *$ \\
\hline Quintile group 3 & -2.9 & 232.7 & 4,255 & $* * *$ \\
\hline Quintile group 4 & -37.2 & 348.8 & 4,682 & $* * *$ \\
\hline Highest quintile group & -219.1 & 861.8 & 4,270 & $* * *$ \\
\hline \multicolumn{5}{|l|}{ Periods of negative growth } \\
\hline Total population & -55.83 & 541.7 & 30,927 & $* * *$ \\
\hline Breakdown by initial reported earnings quintile group & $\mathrm{H}_{02}$ : ***; & & & \\
\hline Lowest quintile group & 223.2 & 499.7 & 6,294 & $* * *$ \\
\hline Quintile group 2 & -11.6 & 181.5 & 6,135 & $* * *$ \\
\hline Quintile group 3 & -37.8 & 218.9 & 6,530 & $* * *$ \\
\hline Quintile group 4 & -81.9 & 318.2 & 5,974 & $* * *$ \\
\hline Highest quintile group & -387.8 & 932.9 & 5,994 & $* 2 *$ \\
\hline
\end{tabular}

Pooled data for Argentina

***, $* *, * \mathrm{H}_{0 \mathrm{j}}$ rejected at $1,5,10 \%$ of significance

$\mathrm{H}_{01}$ : mean equal to zero, $\mathrm{H}_{02}$ : equality of means by groups

Earnings are measured in 1999 pesos. Source: Authors' calculations based on Encuesta Permanente de Hogares (1996-2003)

The results using predicted earnings differ qualitatively from the ones using initial reported earnings and also differ across the three countries. In the case of Argentina, earnings change is usually related significantly to predicted earnings, and all of the significant coefficients are negative. Thus, in Argentina, the results using predicted earnings confirm the results using initial 
reported earnings: divergence is rejected in favor of convergence or neutrality of earnings changes. A similar conclusion is obtained when looking at proportional earnings changes as approximated by changes in log-earnings. However, in the case of Mexico, earnings change is related significantly to predicted earnings only occasionally, and the coefficients change sign. Thus, in Mexico, convergence always appears for initial reported earnings; but for predicted earnings, the earnings changes are significantly convergent in a small number of cases, especially after the 1994 Peso crisis, significantly divergent in a small number of cases, and insignificant in the great majority of cases.

Table 2 Average earnings changes by initial reported earnings quintile group

\begin{tabular}{|c|c|c|c|c|}
\hline & Mean & Std. Dev. & Obs. & $\mathrm{H}_{01}$ \\
\hline \multicolumn{5}{|l|}{ Positive and negative growth years combined } \\
\hline Total population & -87 & $4,889.1$ & 286,062 & $* * *$ \\
\hline Breakdown by initial reported earnings quintile group & $\mathrm{H}_{02}: * * *$ & & & \\
\hline Lowest quintile group & 992 & $2,202.6$ & 57,216 & $* * *$ \\
\hline Quintile group 2 & 513 & $2,052.4$ & 57,209 & *** \\
\hline Quintile group 3 & 351 & $2,515.7$ & 57,243 & $* * *$ \\
\hline Quintile group 4 & 51 & $3,276.7$ & 57,188 & $* * *$ \\
\hline Highest quintile group & $-2,342$ & $9,305.0$ & 57,206 & $* * *$ \\
\hline \multicolumn{5}{|l|}{ Periods of Positive Growth } \\
\hline Total population & -38 & $4,890.2$ & 245,404 & $* * *$ \\
\hline Breakdown by initial reported earnings quintile group & $\mathrm{H}_{02}: * * *$ & & & \\
\hline Lowest quintile group & 1,004 & $2,208.5$ & 49,086 & $* * *$ \\
\hline Quintile group 2 & 534 & $2,095.1$ & 49,080 & $* * *$ \\
\hline Quintile group 3 & 378 & $2,517.2$ & 49,084 & $* * *$ \\
\hline Quintile group 4 & 103 & $3,327.8$ & 49,102 & $* * *$ \\
\hline Highest quintile group & $-2,210$ & $9,306.9$ & 49,052 & $* * *$ \\
\hline \multicolumn{5}{|l|}{ Periods of negative growth } \\
\hline Total population & -384 & $4,872.4$ & 40,658 & $* * *$ \\
\hline Breakdown by initial reported earnings quintile group & $\mathrm{H}_{02}: * * *$ & & & \\
\hline Lowest quintile group & 913 & $2,161.7$ & 8,133 & $* * *$ \\
\hline Quintile group 2 & 401 & $1,809.0$ & 8,135 & $* * *$ \\
\hline Quintile group 3 & 146 & $2,237.9$ & 8,127 & $* * *$ \\
\hline Quintile group 4 & -290 & $3,239.7$ & 8,153 & $* * *$ \\
\hline Highest quintile group & $-3,096$ & $9,248.7$ & 8,110 & $* * *$ \\
\hline
\end{tabular}

Pooled data for Mexico

$* * *,{ }^{* *},{ }^{*} \mathrm{H}_{0 \mathrm{j}}$ rejected at $1,5,10 \%$ of significance

$\mathrm{H}_{01}$ : mean equal to zero, $\mathrm{H}_{02}$ : equality of means by groups

Earnings are measured in 2002 pesos for Mexico. Source: Authors' calculations based on Encuesta Nacional de Empleo Urbano (1987-2004) and Encuesta Nacional de Ocupación y Empleo (2005-2010)

In the log-earnings specification, most of the coefficients for Mexico are statistically insignificant. Finally, in the case of Venezuela, the results for predicted earnings are also mixed: earnings change 
is significantly and negatively related to predicted earnings in seven panels, significantly and positively related to predicted earnings in one panel, and insignificant in six panels. In contrast, most of the coefficients in the model with predicted proportional changes are statistically insignificant. When using predicted earnings as explanatory variable, coefficients become much smaller, within the $[-0.3,0.3]$ range, and non-significant in many cases; rather than the $[-0.8,-0.3]$ range observed when using reported initial earnings. In other words, the strong convergence patterns become much weaker or even neutral.

The fact that for Mexico and Venezuela, several coefficients of the predicted earnings variable are negative and statistically significant when working with earnings in levels but

Table 3 Average earnings changes by initial reported earnings quintile group

\begin{tabular}{|c|c|c|c|c|}
\hline & Mean & Std. Dev. & Obs. & $\mathrm{H}_{01}$ \\
\hline \multicolumn{5}{|l|}{ Positive and negative growth years combined } \\
\hline Total population & $-9,518$ & 250 & 152,747 & $* * *$ \\
\hline Breakdown by initial reported earnings quintile group & $\mathrm{H}_{02}: * * *$ & & & \\
\hline Lowest quintile group & 32,552 & 58,437 & 32,129 & $* * *$ \\
\hline Quintile group 2 & 5,672 & 49,228 & 33,661 & $* * *$ \\
\hline Quintile group 3 & $-4,422$ & 50,900 & 32,650 & $* * *$ \\
\hline Quintile group 4 & $-15,284$ & 70,258 & 25,446 & $* * *$ \\
\hline Highest quintile group & $-74,754$ & 172,970 & 28,861 & $* * *$ \\
\hline \multicolumn{5}{|l|}{ Periods of positive growth } \\
\hline Total population & $-3,998$ & 87,679 & 72,617 & $* * *$ \\
\hline Breakdown by initial reported earnings quintile group & $\mathrm{H}_{02}: * * *$ & & & \\
\hline Lowest quintile group & 34,806 & 58,207 & 14,923 & $* * *$ \\
\hline Quintile group 2 & 8,653 & 50,777 & 17,338 & $* * *$ \\
\hline Quintile group 3 & $-1,456$ & 43,940 & 13,989 & $* * *$ \\
\hline Quintile group 4 & $-7,585$ & 67,932 & 12,185 & $* * *$ \\
\hline Highest quintile group & $-59,721$ & 147,905 & 14,182 & $* * *$ \\
\hline \multicolumn{5}{|l|}{ Periods of negative growth } \\
\hline Total population & $-14,522$ & 105,486 & 80,130 & $* * *$ \\
\hline Breakdown by initial reported earnings quintile group & $\mathrm{H}_{02}: * * *$ & & & \\
\hline Lowest quintile group & 30,597 & 58,567 & 17,206 & $* * *$ \\
\hline Quintile group 2 & 2,505 & 47,324 & 16,323 & $* * *$ \\
\hline Quintile group 3 & $-6,645$ & 55,447 & 18,661 & $* * *$ \\
\hline Quintile group 4 & $-22,357$ & 71,605 & 13,261 & *⿻一; * * \\
\hline Highest quintile group & $-89,278$ & 193,033 & 14,679 & $* * *$ \\
\hline
\end{tabular}

Pooled data for Venezuela

$* * *, * *,{ }^{*} \mathrm{H}_{0 j}$ rejected at $1,5,10 \%$ of significance

$\mathrm{H}_{01}$ : mean equal to zero, $\mathrm{H}_{02}$ : equality of means by groups

Earnings are measured in 1996 bolivares for Venezuela. Source: Authors' calculations based on Encuesta de Hogares por Muestreo (1995-2004) for Venezuela 
insignificant when working with the logarithmic specification indicates that in those periods earnings changes were negatively related to our constructed measure of longer-term earnings advantage, yet the losses were proportional to predicted longer-term advantage. ${ }^{15}$

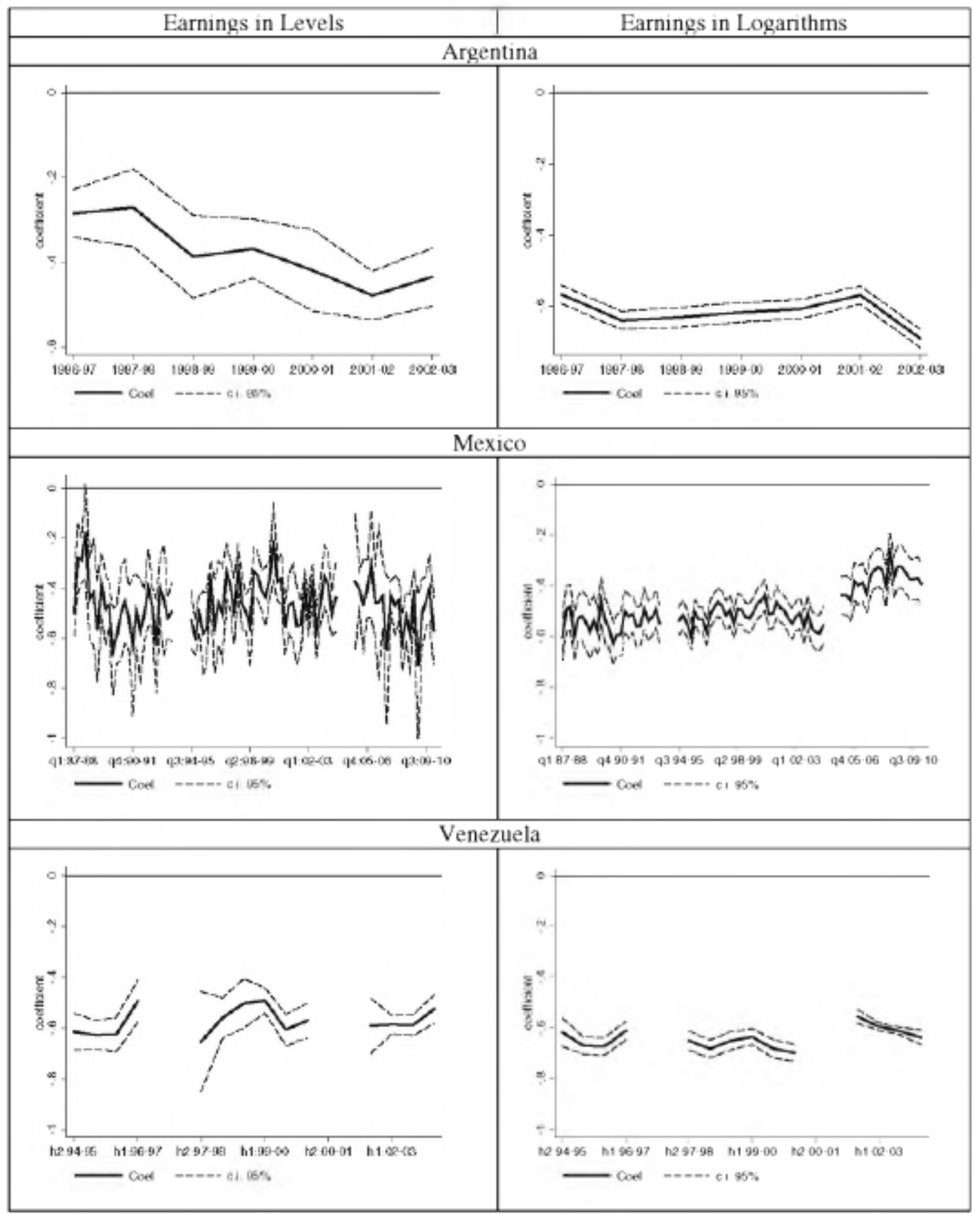

Fig. 1 Regression coefficients of earnings change in levels and logs on initial reported earnings in levels and logs, with $95 \%$ confidence intervals 
In sum, in our three countries, the divergence hypothesis for earnings receives no support at all when using initial reported earnings and only infrequent support when using predicted earnings in pesos or bolivares. In particular, when using initial reported earnings in each country, we find significant convergence both in logs and in levels. When using predicted permanent earnings, the coefficient is not significantly different from zero in most cases, and only in very few cases do we find statistically significant divergence in earnings.

\subsection{Regression-based tests: symmetry of gains and losses}

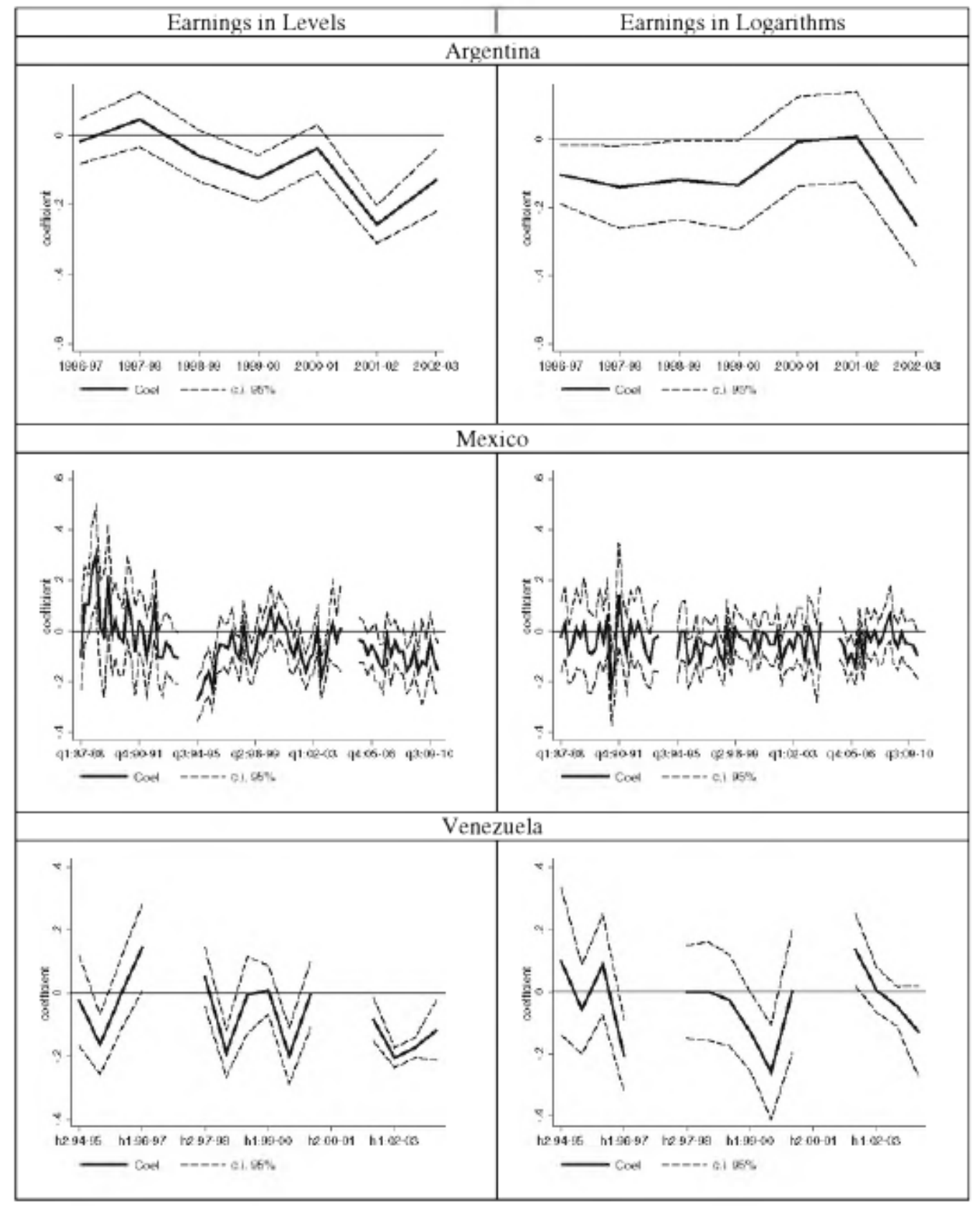

Fig. 2 Regression coefficients of earnings change in levels and logs on initial predicted earnings in levels and logs, with $95 \%$ confidence intervals. Predictions based on time-invariant characteristics 
As already discussed, our three countries all experienced periods of economic growth as well as periods of economic decline. The second question is whether when positive growth and negative growth years are compared, those income groups for whom earnings changes are the most positive when the economy is growing are those for whom earnings changes are the least positive or the most negative when the economy is contracting. When the pattern of gains and losses is not symmetric, we adopt the following terminology: if the same individuals gain significantly more regardless of whether the economy is growing or contracting, the pattern of gains and losses is said to be "structural." Alternatively if the gains for different groups are not significantly different from one another in positive growth and/or in negative growth periods; such a pattern is said to be "insignificant."

Table 4 Earnings change regressions by periods of positive and negative GDP growth

\begin{tabular}{|c|c|c|c|c|}
\hline & \multicolumn{2}{|c|}{$\begin{array}{l}\text { Reported earnings } \\
\text { OLS }\end{array}$} & \multicolumn{2}{|c|}{$\begin{array}{l}\text { Predicted earnings } \\
2 \text { SLS }\end{array}$} \\
\hline & $\Delta$ Earn & $\Delta \ln ($ Earn $)$ & $\Delta$ Earn & $\Delta \ln ($ Earn $)$ \\
\hline Initial y & $\begin{array}{l}-0.29^{* * *} \\
(0.02)\end{array}$ & & $\begin{array}{l}-0.006 \\
(0.02)\end{array}$ & \\
\hline Initial $\ln (y)$ & & $\begin{array}{l}-0.62^{\text {**** }} \\
(0.01)\end{array}$ & & $\begin{array}{l}-0.14^{* * *} \\
(0.038)\end{array}$ \\
\hline Initial $y{ }^{*} N G$ & $\begin{array}{l}-0.12^{* * *} \\
(0.03)\end{array}$ & & $\begin{array}{l}-0.12^{* * *} \\
(0.03)\end{array}$ & \\
\hline Initial $\ln (y)^{*} N G$ & & $\begin{array}{l}0.019^{*} \\
(0.01)\end{array}$ & & $\begin{array}{l}0.075 \\
(0.05)\end{array}$ \\
\hline$N G$ & $\begin{array}{l}14.67 \\
(15.66)\end{array}$ & $\begin{array}{l}-0.40^{\text {k***}} \\
(0.06)\end{array}$ & $\begin{array}{l}7.19 \\
(13.13)\end{array}$ & $\begin{array}{l}-0.75^{\text {***}} \\
(0.26)\end{array}$ \\
\hline Constant & $\begin{array}{l}157.7^{* * *} \\
(11.36)\end{array}$ & $\begin{array}{l}3.32^{* 8 *} \\
(0.044)\end{array}$ & $\begin{array}{l}7.82 \\
(10.03)\end{array}$ & $\begin{array}{l}0.87^{* * *} \\
(0.20)\end{array}$ \\
\hline$N$ & 53,349 & 53,349 & 53,349 & 53,349 \\
\hline$R$-squared & 0.22 & 0.31 & 0.006 & 0.005 \\
\hline
\end{tabular}

Pooled data for Argentina

${ }^{* * *},{ }^{* *},{ }^{*} \mathrm{H}_{0}: \beta=0$ rejected at $1,5,10 \%$ level of significance. Robust std. err. in parentheses

$y$ : Earnings measured in 1999 pesos

$N G$ is a dummy variable for periods with negative GDP growth

Initial $y$ and Initial $\ln (y)$ represent the coefficient of initial earnings and log-earnings respectively during periods of positive economic growth. To obtain the corresponding coefficients for periods of negative economic growth sum that coefficient to the one of Initial $y^{*} N G$ (or Initial $\left.\ln (y)^{*} N G\right)$

Predicted initial earnings are based on a First-Stage regression of earnings on age and its square, education and its square, gender, and regional dummies. A similar model applies to log earnings

Authors' calculations based on Encuesta Permanente de Hogares (1996-2003) 
Tables 4, 5 and 6 present the estimations of Eq.5

$$
\Delta Y=\beta_{0}+\beta_{1} Y_{0}+\beta_{2} N G+\beta_{3} Y_{0} * N G+u,
$$

for earnings in levels and in logarithms using initial reported earnings and predicted earnings as alternative measures of initial advantage. To reiterate, these regressions are estimated using pooled data across all years for each economy. Empirically, we observe that the parameter $B 1$ measures the relation between earnings changes and initial earnings during periods of positive economic growth. A quick look across our results tables shows that for virtually all years and all

Table 6 Earnings change regressions by periods of positive and negative GDP growth

\begin{tabular}{|c|c|c|c|c|}
\hline & \multicolumn{2}{|c|}{$\begin{array}{l}\text { Reported earnings } \\
\text { OLS }\end{array}$} & \multicolumn{2}{|c|}{$\begin{array}{l}\text { Predicted earnings } \\
2 \text { SLS }\end{array}$} \\
\hline & $\Delta$ Earn & $\Delta \ln ($ Earn $)$ & $\Delta$ Earn & $\Delta \ln ($ Earn $)$ \\
\hline Initial y & $\begin{array}{l}-0.558^{* * *} \\
(0.013)\end{array}$ & & $\begin{array}{l}-0.090^{* * * *} \\
(0.014)\end{array}$ & \\
\hline Initial $\ln (y)$ & & $\begin{array}{l}-0.627 * * * \\
(0.005)\end{array}$ & & $\begin{array}{l}-0.089^{* * *} \\
(0.025)\end{array}$ \\
\hline Initial $y * N G$ & $\begin{array}{l}-0.03109 \\
(0.025)\end{array}$ & & $\begin{array}{l}-0.028^{* * * *} \\
(0.02)\end{array}$ & \\
\hline Initial $\ln (y) * N G$ & & $\begin{array}{l}0.016^{* * * *} \\
(0.007)\end{array}$ & & $\begin{array}{l}0.124^{* * * *} \\
(0.036)\end{array}$ \\
\hline$N G$ & $\begin{array}{l}967.4 \\
(2,212.8)\end{array}$ & $\begin{array}{l}-0.249^{\text {***** }} \\
(0.079)\end{array}$ & $\begin{array}{l}-6,497.3^{* * * *} \\
(1,585.5)\end{array}$ & $\begin{array}{l}-1.533^{* * * *} \\
(0.360)\end{array}$ \\
\hline Constant & $\begin{array}{l}41050^{* * * *} \\
(980.9)\end{array}$ & $\begin{array}{l}6.103^{* * *} \\
(0.055)\end{array}$ & $\begin{array}{l}3,261.1^{* * *} \\
(1,035.4)\end{array}$ & $\begin{array}{l}0.865^{* * *} \\
(0.248)\end{array}$ \\
\hline$N$ & 152,747 & 152,747 & 152,747 & 152,747 \\
\hline$R$-squared & 0.36 & 0.30 & 0.12 & 0.03 \\
\hline
\end{tabular}

Pooled data for Venezuela

***, $* *,{ }^{*} \mathrm{H}_{0}: \beta=0$ rejected at $1,5,10 \%$ level of significance. Robust std. err. in parentheses

$y$ : Earnings measured in 1996 bolivares

$N G$ is a dummy variable for periods with negative GDP growth

Initial $y$ and Initial $\ln (y)$ represent the coefficient of initial earnings and log-earnings respectively during periods of positive economic growth. To obtain the corresponding coefficients for periods of negative economic growth sum that coefficient to the one of Initial $y^{*} N G$ (or Initial $\left.\ln (y)^{*} N G\right)$

Predicted initial earnings are based on a First-Stage regression of earnings on age and its square, education and its square, gender, and regional dummies. A similar model applies to log earnings

Authors' calculations based on Encuesta de Hogares por Muestreo (1995-2004) 
of our econometric specifications, there is convergence (i.e. $\beta_{1}<0$ ) during periods of economic growth. ${ }^{16}$

Given the finding of convergence during periods of economic growth, if symmetry of gains and losses is to hold, then we must have divergence in periods with negative growth, i.e., $\beta_{1}+\beta_{3} \geq 0$, or equivalently $\beta_{3} \geq-\beta_{1}>0$. In Tables 4,5 and 6 the coefficient $\beta_{3}$ appears either under the label "Initial $\mathrm{y} * \mathrm{NG}$ " or "Initial $\ln (\mathrm{y}) * \mathrm{NG}$ ".

Looking first at the results in levels (i.e., pesos or bolivares), the coefficient is always negative. We can thus infer that earnings changes are not symmetric if we look at the specifications using earnings (either reported or predicted) in levels.

Turning to the logarithmic specifications, we see that only in the case of predicted logearnings in Venezuela does the condition $\beta_{3} \geq-\beta_{1}>0$ hold. To formally test the symmetry hypothesis we perform the t-test proposed in Eq. 6. The results for this test are presented in Table 7. There we see that in nearly all the specifications, earnings changes are asymmetric, namely the income groups that gain the most (lose the least) during periods of economic growth are the same ones that gain the most (lose the least) during periods of economic downturn. There are two exceptions, which correspond to the specification for predicted log-earnings in Venezuela and Mexico. As previously mentioned in the case of Venezuela there is divergence in predicted logearnings during periods with negative growth and convergence during periods with positive growth. In the case of Mexico (under this same specification) there is convergence throughout but the convergence coefficient for periods with negative growth is not statistically significant, so we cannot reject the hypothesis of symmetry.

Table 7 Test of symmetry hypothesis

\begin{tabular}{|c|c|c|c|c|}
\hline & \multicolumn{2}{|c|}{ Reported earnings } & \multicolumn{2}{|c|}{ Predicted earnings } \\
\hline & Levels & Logs & Levels & Logs \\
\hline Argentina & $19.23^{* * *}$ & $87.00^{* * * *}$ & $6.82^{* * *}$ & $1.97 * *$ \\
\hline Mexico & $24.43 * * *$ & $44.88^{* * *}$ & $7.47 * * *$ & 0.67 \\
\hline Venezuela & $27.26^{* * * *}$ & 118.09 *承* & 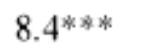 & -1.34 \\
\hline
\end{tabular}

One-sided t-statistics

$\mathrm{H}_{0}$ : Individuals that experience larger earnings when the economy is growing are the same as those that experience larger earnings losses when the economy is contracting

We have obtained three main findings. First, using pooled data, both for levels and logs, and reported earnings we observe strong convergence (i.e. a coefficient around -0.50) but no evidence of symmetry in any country. Second, using pooled data and our preferred specification with predicted permanent earnings, we find evidence of weak convergence (i.e., a coefficient in the range $[-0.1,0.0])$, but no evidence of symmetry when using changes in levels. Third, when using changes in logs we still find weak convergence in all countries, but we fail to reject the 
symmetry hypotheses in Mexico and Venezuela. Divergence and symmetry of mobility are overwhelmingly rejected.

\subsection{Reconciling the panel and cross-section results}

The reader may have noticed a seeming contradiction. We have mentioned that crosssectional absolute and relative inequality had ups and downs in each of our three countries. However, we have also found in the panel data analysis that the mobility patterns are nearly always convergent or neutral, rarely divergent. The cross-sectional inequality findings mean that during several periods those anonymous individuals at the upper end of the earnings distribution gained at least as much in pesos or bolivares, as those at the lower end of the earnings distribution. On the other hand, the mobility evidence compiled from analysis of panel data means that among those particular individuals who are followed over time, those who started at the lower end of the earnings distribution gained at least as much in pesos or bolivares as those who started higher in the earnings distribution. How can these two findings be reconciled?

It is important to note, contrary to what many observers may believe, that convergent mobility does not imply falling inequality. For instance, Furceri [15] and Wodon and Yitzhaki [31] both show that "beta-convergence" (a negative relationship between change in log-income and initial log-income) is mathematically compatible with "sigma- divergence" (i.e., rising inequality as measured by the variance of logs). A detailed reconciliation between different measures of panel income change and relative inequality change is presented in Duval-Hernandez et al. [12]. In that work it is shown that rising inequality can be compatible with convergent earnings changes if earnings changes are large enough so that some individuals switch positions in a widening income distribution. ${ }^{17}$

To examine this mechanism, we explore more closely what happens with the distributions of earnings and earnings changes. In particular, for each country we select a period with rising absolute and relative inequality and positive economic growth, and we examine the distribution of earnings looking at the individuals anonymously and in a panel setting. For these periods in the three countries, we perform two sets of calculations.

The first set of calculations, presented in Fig. 3, displays the initial and final period logearnings of 27 illustrative individuals. To select these individuals, we split the population according to the quintiles of the initial period earnings distribution, and then for each quintile group we randomly select an individual located at the 5th, 25th, 50th, 75th, and 95th percentile of a given quintile group. ${ }^{18}$ We also select two individuals non-randomly, namely, the one individual with the highest initial earnings and the one with the highest final earnings. We plot the location of initial period log-earnings (top line) and final period log-earnings (bottom line), looking at the distributions anonymously (left column) and tracking individuals over time (right panel). ${ }^{19}$

As previously mentioned, relative and absolute inequality rose in these periods. Yet behind the rise in inequality, the figure tracking individuals over time reveals two important facts, namely: a) earnings change substantially for a minority of earners, and b) most of these large earnings changes occur in a crossing pattern, resulting in convergent mobility. 
In other words, part of the reason why we find non-divergent earnings in spite of studying periods with rising inequality is that in the panel distribution of earnings there are a few individuals experiencing large reversals of fortunes. Whether such large reversals of fortunes are due to transitory shocks, measurement error, or some other more lasting force is something that deserves further research in countries with more observations on individuals' incomes over time and, ideally, with both survey and administrative data.

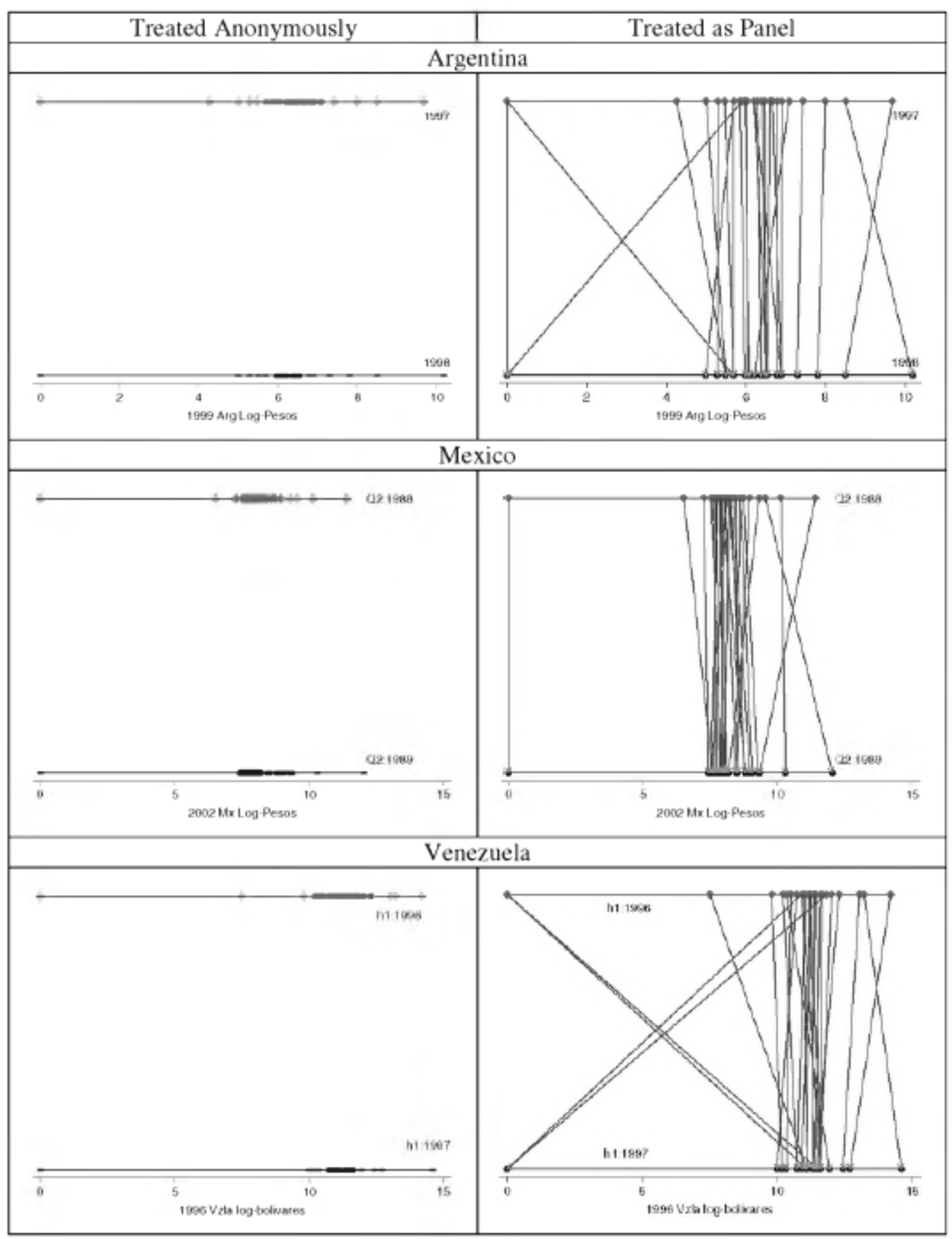

Fig. 3 Earnings distributions for 27 illustrative individuals in a period of rising inequality 
The second set of calculations includes the full samples for the selected panels. For each country, we have classified workers in two ways, a cross-sectional approach and a panel data approach. The cross-sectional approach classifies workers into those belonging to the top quintile of real earnings in each year according to their earnings in that year and everyone else; it then calculates the mean earnings gain for these two cross-sectional (or anonymous) groups. The results, presented in column 2 of Table 8 , show that in each country the cross-sectional top quintile group always gained the most. By contrast, the panel data approach classifies workers according to their initial earnings, and average earnings changes over time are then calculated for those individuals who started in the top quintile group and the bottom $80 \%$ regardless of where they ended up. The pattern from this second approach, presented in the last column of that table, is the exact opposite to the previous one, namely in each country the panel people who gained the most were those who started in the lowest earnings quintiles. Remember: these calculations are for the exact same people. What differs is the method for calculating earnings changes, not the sample of earners.

In summary, not only can cross-sectional methods and panel data methods produce qualitatively opposite pictures of who gains the most when economic growth takes place but they do produce qualitatively opposite pictures for our three countries.

Table 8 Earnings changes by quintile group: cross-section and panel results

\begin{tabular}{lll}
\hline Initial earnings group & $\begin{array}{l}\text { Mean earnings change } \\
\text { in the cross section }\end{array}$ & $\begin{array}{l}\text { Mean earnings change of those } \\
\text { who started in this group }\end{array}$ \\
\hline Argentina & 19.4 & 70.5 \\
Bottom $80 \%$ & 113.9 & -181.8 \\
Top 20\% & 322 & $1,014.7$ \\
Mexico & 1,865 & -686.7 \\
Bottom $80 \%$ & & 18,143 \\
Top 20\% & $-1,131$ & $-38,293$ \\
Venezuela & 16,064 & \\
Bottom $80 \%$ & Top 20\% &
\end{tabular}

For Argentina the data refer to the 1997-1998 Panel. Earnings are measured in 1999 Arg. Pesos

For Mexico the data refer to the second quarter of 1988-89 Panel. Earnings are measured in 2002 Mex. Pesos For Venezuela the data refer to the first semester of 1996-97 Panel. Earnings are measured in 1996 Bolívares 


\section{Conclusions}

In this paper, we have used panel data for Argentina, Mexico, and Venezuela to ask who has larger earnings changes in local currency units: those who started at the top of the distribution or those who started at the bottom? Given that economic growth was positive in most years and that relative earnings inequality rose often, and given our sense that most people remain approximately where they began within the income distribution, we expected to find two patterns in panel data: first, that earnings changes would be divergent in percentages on several occasions, and second that earnings changes would be divergent in pesos or bolivares all or nearly all the time - that is, on average, the higher is initial earnings, the higher is mean earnings gain in national currency units. But we found the opposite: convergent earnings changes in pesos or bolivares nearly all the time. Try though we might to get a predominantly divergent pattern of earnings changes in the three countries using a number of different specifications, we could not. Divergence is not the norm; convergence is. Specifically, we found that the divergence of earnings hypothesis receives no support at all when looking at a measure of initial reported earnings (or log-earnings). When we used a measure of predicted earnings that approximates longer-term earnings (and hence is less sensitive to mean-reverting transitory shocks) we obtained only scant support for the divergence hypothesis in the case of Mexico and Venezuela and no support at all in the case of Argentina. Most of the changes in earnings were either unrelated or negatively related to this measure of longer-term advantage.

We also tested whether the income groups that gain the most when the economy is growing are the ones that gain the most or gain the least when the economy is contracting. Support for the hypothesis of symmetric mobility was found only in Venezuela and for only one of the econometric specifications, namely the model of log-predicted earnings. In Mexico, for that same specification, we found no statistically significant pattern. In all other specifications, rather than symmetry, we found that earnings changes were "structural" in the sense that poorer individuals gained more than others regardless of whether the economy was growing or contracting. Therefore, in our three countries, the symmetry of mobility hypothesis was overwhelmingly rejected.

Finally, contrary to common perception, our research shows that periods of rising inequality are not necessarily associated with divergence in earnings among a panel of people, either unconditionally or after controlling for the potential confounding effects of transitory shocks adjusting back to the mean and of measurement error.

Overall, the analysis performed in this paper shows that much can be learned by analyzing panel data, knowledge that would not have been obtained by analyzing comparable cross sections. In the future, researchers would do well to perform both panel data analysis and cross-section analysis. Both types of analysis are meaningful. They are, however, different from one another.

Acknowledgments We would like to acknowledge the valuable comments of two anonymous referees and the Editor of this journal. Also, we would like to thank Yang Song and David Jaume for excellent research assistance. 


\section{References}

1. Henry, A.: Politics and the Professors. Brookings Institution, Washington, DC (1978).

2. Acemoglu, D., Autor, D.H.: Skills, tasks and technologies: Implications for employment and earnings. In: Ashenfelter, O., Card, D.E. (eds.) Handbook of Labor Economics, vol. 4, pp. 1043-1171. Elsevier, Amsterdam (2011).

3. Atkinson, A.B., Bourguignon, F. (eds.): Handbook of Income Distribution, vol. 2. Elsevier, Amsterdam (forthcoming).

4. Antman, F., McKenzie, D.J.: Earnings mobility and measurement error: A pseudo-panel approach. Econ. Dev. Cult. Chang. 56(1), 125-161 (2007).

5. Azariadis, C., Stachurski, J.: Poverty Traps. In: Aghion, P., Durlauf, S.N. (eds.) Handbook of Economic Growth, vol. 1A, pp. 295-384. Elsevier Science, Amsterdam (2005).

6. Baulch, B. (ed.): Why Poverty Persists: Poverty Dynamics in Asia and Africa. Edward Elgar, Cheltenham (2011).

7. Bound, J., Brown, C., Duncan, G.J., Rodgers, W.L: Evidence on the validity of crosssectional and longitudinal labor market data reviewed. J. Labor Econ. 12(3), 345-368 (1994).

8. Bound, J., Brown, C., Mathiowetz, N.: Measurement error in survey data. In: Heckman, J., Leamer, E. (eds.) Handbook of Econometrics, vol. 5, pp. 3705-3843. Elsevier Science, Amsterdam (2001).

9. Cuesta, J., Nopo, H., Pizzolitto, G.:Using pseudo-panels to measure income mobility in Latin America. Rev. Income Wealth 57(2), 224-246 (2011).

10. Deaton, A.: The Analysis of Household Surveys: A Microeconometric Approach to Development Policy. The Johns Hopkins University Press, Baltimore (1997).

11. Duval Hernandez, R.: Dynamics of Labor Market Earnings and Sector of Employment in Urban Mexico, 1987-2002. Ph.D. dissertation. Cornell University (2006).

12. Duval-Hernandez, R., Fields, G.S., Jakubson, G.H.: Changing Income Inequality and Panel Income Changes in Times of Economic Growth and Economic Decline, unpublished manuscript (2014).

13. Fields, G.S., Duval-Hernandez, R., Freije, S., Sanchez Puerta, M.L.: Intragenerational income mobility in Latin America. Economia 7(2), 101-143 (2007).

14. Fields, G.S., Sanchez Puerta, M.L.: Earnings mobility in times of growth and decline: Argentina from1996 to 2003. World Dev. 38(9), 870-880 (2010).

15. Furceri, D.: $\beta$ and a convergence: A mathematicalrelation of causality. Econ. Lett. 89, 212215 (2005). 
16. Gasparini, L., Lustig, N.: The rise and fall of income inequality in Latin America. In: Ocampo, J.A., Ros, J. (eds.) Oxford Handbook of Latin American Economics. Oxford University Press, Oxford (2011).

17. Glewwe, P.: How Much of Observed Economic Mobility is Measurement Error? IV Methods to Reduce Measurement Error Bias, with an Application to Vietnam. World Bank Econ Rev 26(2), 236-264 (2010).

18. Gottschalk, P.: Earnings mobility: Permanent change or transitory fluctuations? Rev. Econ. Stat. 64(3), 450-456 (1982).

19. Gottschalk, P., Huynh, M.: Are earnings inequality and mobility overstated? The impact of nonclassical measurement error. Rev. Econ. Stat. 92(2), 302-315 (2010).

20. Grimm, M.: Removing the anonymity axiom in assessing pro-poor growth. J. Econ. Inequal. 5(2), 179197 (2007).

21. Jantti, M., Jenkins, S.P.: Income Mobility. In: Atkinson, A.B., Bourguignon, F. (eds.) Handbook of Income Distribution, vol. 2. Elsevier, Amsterdam (forthcoming).

22. Krebs, T., Krishna, P., Maloney, W.F.: Income Risk, Income Mobility and Welfare IZA Discussion Paper No 7056 (2012).

23. Kuznets, S.: Economic growth and income inequality. Am. Econ. Rev. XLV(March), 1-28 (1955).

24. Meade, J.E.: The Just Economy. Allen and Unwin, London (1976).

25. Merton, R.E.: The Matthew effect in science. Science, 159 (1968).

26. Moffitt, R.A., Gottschalk, P.: Trends in the transitory variance of earnings in the United States. Econ. J. 112(March), C68-C73 (2002).

27. Palmisano, F., Peragine, V.: The distributional incidence of growth: A social welfare approach. Rev. Income Wealth (2014).

28. Ravallion, M.: Pro-Poor Growth: A Primer. World Bank Policy Research Working Paper 3242 (2004).

29. Ravallion, M.: A Comparative Perspective on Poverty Reduction in Brazil, China and India. World Bank Policy Research Working Paper 5080 (2009).

30. Sanchez Puerta, M.L.: Earnings Mobility in Urban Argentina. Ph.D. dissertation. Cornell University (2005).

31. Wodon, Q., Yitzhaki, S.: Convergence forward and backward? Econ. Lett. 92, 47-51 (2006). 